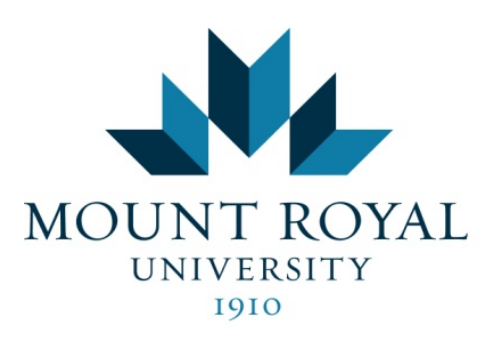

Mount Royal Undergraduate Education Review
Department of Education and Schooling

Volume 1(1)

Spring 2014

\title{
Technology as a resource: Increasing engagement in learning and developing 21st century skills
}

Jessica Lukey, Mount Royal University

\begin{abstract}
The purpose of this research study was to help inform the researcher’s future practice as a teacher on the influence of technology on young learners. The question of inquiry pertained to define how technology has initiated and increased student engagement within their learning, and through this, how technology has specifically influenced the creation of the 21st century learner. By beginning the inquiry through a literature review on the theme of technology and student engagement, the researcher was able to gain an understanding that technology is the motivator for children in developed, and even in undeveloped countries. In order to assess the relationship of technology and student engagement in learning, along with how digital devices influence the creation of 21st century learners, the researcher surveyed a variety of teacher candidates and university students to draw conclusions. From the research findings of the study, the researcher concluded that students were attracted to technology as it is a tool that is convenient in organizing information, and is efficient in making data easier to allocate. Therefore, the skills that technology imparted upon 21st century learners from the findings were allowing students to
\end{abstract}


become self-directed learners, access and, evaluate information through critical thinking and solving data to become more engaged thinkers, and influencing leadership and collaboration skills.

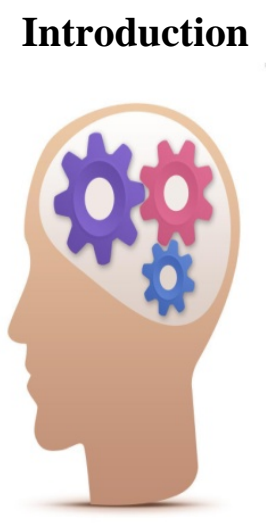

Figure 1. Creative thought processes

Upon beginning research on developing an inquiry question, the researcher was given the opportunity in her $2^{\text {nd }}$ year educational technology course to watch a short documentary on the future of learning entitled How Do We Make Learning Relevant to Students (Good, 2012). While watching this video the researcher became engaged with the question of how technology corresponds to student engagement and relevance to learning (Good, 2012). In schools, classrooms are becoming more digitally-driven, where students are becoming more technologically advanced in their learning. As these students take the shape of becoming more technologically advanced and engaged with their learning, Dr. Sugata Mitra in the documentary, makes the claim that the curriculum/skills of the future will be comprised of the following:

1. Reading comprehension

2. Information search and retrieval skills

3. How to believe (armor against doctrine)

By thinking about this new context of the curriculum and skills of the future as a result of 
classrooms and students becoming more technologically advanced, the researcher found herself becoming more intrigued by this new context of future learning, which created her context of inquiry. The context of inquiry not only stems from the claims made by the educational researchers in the video, but also through the researcher's own personal use of technology.

In the winter 2014 semester, the researcher personally decided to use her laptop computer and other various technological devices for her classes at Mount Royal University, as opposed to the traditional methods of using pen and paper. As the researcher entered her third week of the semester, she found herself more intrigued to do assignments using her computer as opposed to pen and paper. Furthermore, the researcher found that she could work on assignments just about anywhere she went as she was able to bring her laptop everywhere with herself, as opposed to carrying five large binders around. Throughout the whole experiment, the researcher concluded that overall she found herself more engaged in her classes as she was able to participate more in the lecture or workshops, as opposed to writing notes on paper with her head down. Within this context, the researcher believes that her educational technology experiment in the winter 2014 semester has guided her inquiry question as to why others, along with herself, are more engaged to learn when integrating the use of various technological devices.

By keeping Dr Sugata Mitra's curriculum and skills of the future in mind, the researcher's question of inquiry pertains to define how technology has initiated and increased student engagement within their learning, and through this, how has technology specifically influenced the creation of the 21st century learner?

As the researcher has become more engaged in her learning over the past winter 2014 semester by using technological devices to aid her learning, her question of inquiry similarly relates to elementary education as these classrooms of students are also becoming more exposed 
to technology in their learning. Through her school placement experiences, the researcher has observed that schools are beginning to incorporate more laptop computers and other various digital devices, like iPads, into the school as class-sets to be shared or owned strictly by one teacher for their set of students. Within this context, schools are incorporating the use of technological devices as student learning supporters to help them become engaged within their learning, as opposed to the traditional method of teaching, via lectures, copying notes, etc. This new era of teaching focuses more on student motivation and how they learn best. Technology allows for greater motivation for students to want to learn new things and to expand their comprehension and understanding of ideas learned in the classroom environment.

As it is important to incorporate technology into the classroom as society advances along in its growth of technology, the researcher's question of inquiry will help inform her future practice as a teacher as it will help herself to gain a better understanding of why others, not just herself, are more engaged with their learning when incorporating the use of technology. Furthermore, it will allow herself to either incorporate the use of technology in greater or smaller amounts in her future practice, dependent upon the findings of the research study. From the researcher's stance, the incorporation of the use of technology in the classroom can be an asset which aides student learning. It will be interesting to observe actual teacher practitioner's viewpoint on the use of technology, and whether or not they truly feel it is an asset to student engagement in learning.

Although the question of inquiry pertains to define how technology promotes student engagement in their learning, it also focuses on how technology has specifically influenced the creation of the 21st century learner. The researcher believes that this second component to the inquiry question plays a very substantial component in her future practice as a teacher, as she is 
hoping that it helps herself to become more aware of the skills from which technology has imparted upon to create the 21st century learner. Furthermore, this will help herself to become aware of the benefits that technology has upon the skill development of learners to help improve their learning, and their capabilities to lead a successful academic life from using technologies sought in society today into the classroom now.

\section{Educational Literature Review}

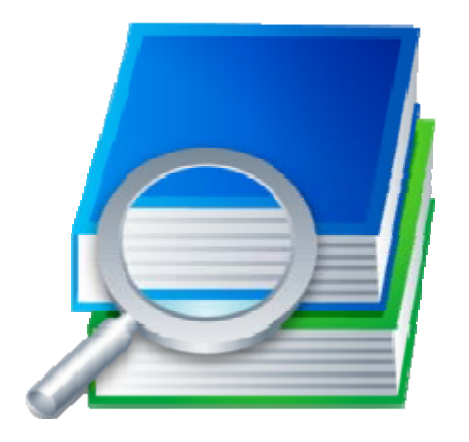

Figure 2. Educational literature review

Student engagement with their learning is the key goal for all teachers to pursue in their practice, as students will showcase a willingness to want to learn and engage in their studies. In the classroom today, the advancement of technology in our day and age is allowing student engagement within their learning to occur, resulting in student motivation and the creation of a new 21st century learner. Back in the day, when our parents were growing up in school, the majority of our parents engaged in traditional methods of teaching, where they primarily sat in rows of desks individually, and listened to the teacher give knowledge and instruction via textbook. These students, our parents, did not have any means of technology to use in their learning, but relied upon the use of books for research matters to gain knowledge. By taking this perspective of how learning occurred a few decades ago to how students are learning in the classroom today, as teachers we are able to gain a background comprehension of how technology 
has advanced to aid in student learning today. Technology is becoming more prominent in the classroom as a result of society building and incorporating the use of technology in people's lives more prominently daily. Within this context, teachers are now incorporating the use of technology in their classroom environment to not only aid in student engagement of learning, but to help prepare them to use these technologies in their everyday lives. Furthermore, the use of technology in the classroom has developed a new criterion of skills, from which students developed, which has ultimately developed a new 21st century learner.

By gaining an understanding of how students learned decades ago in the classroom to today, along with the researcher's personal experiment of solely relying upon the use of technology to aid her learning in the winter 2014 semester, this has pursued herself to lay a foundation upon from which she built the question of inquiry to aid her research study. Within this context, the question of inquiry pertains to define how technology has initiated and increased student engagement with their learning, and through this, how has technology specifically influenced the creation of a 21st century learner? By taking this inquiry question into research, five relevant sources have presented themselves to aid the researcher's understanding of how technology increases student engagement, and has influenced the skill development of the 21st century learner.

The first major theme of the research study sought through the inquiry question is to gain an understanding of how technology has initiated and increased student engagement with their learning. By breaking down the first major theme into research, the researcher has come across three sources that prove to be of relevance to the inquiry research.

Dr. Sugata Mitra in the documentary, The Future of Learning, helped the researcher to define where the future of learning is going, and what it will eventually be composed of (Good, 
2012). Apart from Dr. Mitra, the documentary addresses a number of individuals who have sought to incorporate the use of technology into their practice or develop a new technology for schools to implement, resulting in the belief that technology in the classroom is the future of learning (Good, 2012). In the video, various individuals provide a focused perspective on how educators can provide and make learning relevant to students through technology in all sectors of educational facilities.

As the video showcases the future of learning in the classroom, it presents a careful examination of how learning occurred more than three hundred years ago, and how the classroom has progressed to what is being learned in today's educational facilities (Good, 2012). In doing so, the documentary provides insight into the need for all educators to pursue student motivation into their studies, which can be achieved through engaging students in authentic and hands-on experiences (Good, 2012). By providing more authentic experiences in learning, various individuals in the documentary make the claim that technology provides an engaging experience for students, which is the learning of the future for the 21st century learners.

In the second source of how technology aids student engagement, Dr. Sugata Mitra gave a Technology, Entertainment, and Design (TED) Talk on discussing the importance of technology, specifically computers, to facilitate student engagement and learning (Nameet, 2013). Dr. Mitra addressed the fact that children are motivated to learn and understand how a new technology or an object works when it is unknown with no instructions. As a result of an unknown, children are more motivated to understand the technology, where Dr. Mitra states that a comprehension of the unknown for children is essential for their learning, from which he developed the 'Granny effect’ (Nameet, 2013).

Dr. Mitra conducted multiple case studies of children in remote villages in India and 
other places around the world, where he placed a computer in these remote areas without any tutoring of how the technology alone works (Nameet, 2013). By implanting a camera above to watch the children over a span of five months to a year to try to understand the computer, Dr. Mitra became aware that children were motivated to learn and understand how the computer worked as it was unknown to them (Nameet, 2013). Furthermore, he wanted to investigate the children's comprehension of the computer, and in doing so, he created the 'Granny effect'. The Granny effect was an experiment where older women and teachers from all over the world could videoconference in and ask simple-minded questions about the technology and data on the computer, to help the children gain a comprehension of the technology and data on the digital device, as opposed to the superficial concept of it. In summary, Dr. Mitra addresses the belief that to encourage by asking questions, the Granny effect, will ultimately result in comprehension of the unknown by learning (Nameet, 2013). Furthermore, motivation is a direct result of student engagement with their learning, on the basis of children wanting to understand how an unknown object functions, similarly found in the next research investigation (Nameet, 2013).

In a single-case research study in a grade six classroom where the perceptions of a teacher and their students was used to investigate the motivational affordances of using mobile devices, such as tablets and iPads, Ms. Ciampa (2013) found that students took on the role of becoming 'teachers' and 'experts' of their own learning. As a result of incorporating technology to aid student learning in the classroom, the study found that motivation from the use of mobile devices was the key catalyst to aid student engagement in their learning.

Ciampa (2013), the sole researcher of the study, collaborated with a grade six classroom at St. Martin Catholic Elementary School in Southern Ontario, Canada, to incorporate mobile devices into the curriculum for a span of five months. The participants in the study were twenty- 
four students in a grade six classroom, who ranged from ten to twelve years of age (Ciampa, 2013).

It was Ciampa’s (2013) intent to investigate the question, “How do elementary students and teachers perceive their tablet use and what motivated them to be a tablet user?” (p.1). By laying down a solid question for context, she focused on the students' and teacher's selfperceptions on their experience of using mobile devices in the classroom to aid learning. Through digital recorded interviews with students and the teacher, as well as using findings from the teacher's blog, six key aspects emerged as a result of student motivations in learning from technology, which are as follows; challenge, control, curiosity, recognition, cooperation, and competition. Ciampa (2013) concluded that these six areas emerged as a result of mobile devices enhancing student motivation toward learning, stating the fact the technology is beneficial in the aid of student learning.

Each of these research sources have provided the researcher with a basis of understanding, that motivation is the key component for learners as to why technology has increased and initiated student engagement with their learning. It is from this belief that these three sources emphasize the statement that the unknown in the use of technology, such as programs and the mobile device itself, provides a unique and authentic experience for the student as it is hands-on learning where the student figures out the device or program on their own or in collaboration with peers. Through the learner's initiative to want to understand the unknown, the implementation of technology in the classroom further pursues the question of how technology specifically influences the 21st century learner. Within this, the following two additional sources provide a strong relevance for a basis of understanding the skills that technology has produced upon the 21st century learner. 
In an article detailing the framework of the 21st century skills required for students to become engaged and acquired with throughout their schooling, Larson and Miller (2011) discussed the skills that students in the 21st century classroom will need to develop as a learner. They collaborated together at Kansas State University to address and define what the skills of the 21st century learner are in the classroom, and how educators can help to implement them into the classroom curriculum. Larson and Miller (2011) state that communication and collaboration skills, expertise in technology, innovative and creative thinking skills, and an ability to solve problems define the required 21st century skills, which emphasize "what students can do with knowledge and how they apply what they learn in authentic contexts” (p.84). Within this framework, the two researchers believe an engagement of authentic experiences through the implementation of technology in the classroom will help to provide these 21st century skills of the learner. In doing so, the article also includes an array of a variety of websites and other resources that educators can use for help integrating the framework into content areas of teacher’s curriculum (Larson \& Miller, 2011).

In another article providing a context for the outdated approach of direct teaching, via lectures, Saavedra and Opfer (2012) discuss the need for educators to engage students in more authentic and engaging experiences. They collaborated together to discuss and define nine lessons for how 21st century learning can occur in classrooms by a teacher through their lesson plans, teaching goals, and interacting with students. Together, Saavedra and Opfer (2012) address the need for the incorporation of technology into the classroom environment to enhance and foster the 21st century skill development of students. They believe that the development of 21st century skills is directly associated with the fostering of technology into the classroom, which includes critical thinking and problem solving, collaboration and leadership, agility and 
adaptability, initiative and entrepreneurialism, effective oral and written communication, accessing and analyzing information, and having curiosity and imagination (Saavedra \& Opfer, 2012). They also state that by engaging students in more authentic and engaging experiences through the use of technology, it will prove to be more relevant to learners in their life outside of school, where they are able to apply these new 21st century skills.

Each of the five educational research sources has provided me a broader perspective on my question for inquiry. By drawing and tying conclusions together from these five sources, they have demonstrated to me that motivation of an unknown technology or program is a key component tied to students becoming engaged with their learning. In this developing idea, the research sources illustrate that when students are presented with a new technology that is unknown to them, they become engaged with wanting to figure out and manipulate the device in order to gain a new understanding. This new understanding is otherwise known as learning, where students are motivated to manipulate and gain a comprehension of the unknown, resulting in an appeal to have a desire to learn. Furthermore, the idea of wanting to understand the unknown requires the skills to collaborate, communicate, problem solve, critically think, analyze and assess information, and to display and generate conclusions in a creative manner, a direct result of the skills required for a 21st century learner from technology.

These conclusions from my background literature review helped to set a framework of where my own research and inquiry context will eventually lead too. By gaining an understanding of previous research done in the particular field of the researcher's inquiry, it overall helps to build a foundation of the conclusions that she may be able to draw once she has conducted the research. As well, the background literature will also help to inform the research context and methodology used to draw results of how others in higher educational facilities view 
the engagement of technology in their learning, and what they perceive are the skills that technology has influenced in the creation of the 21st century learner.

\section{Research Context}

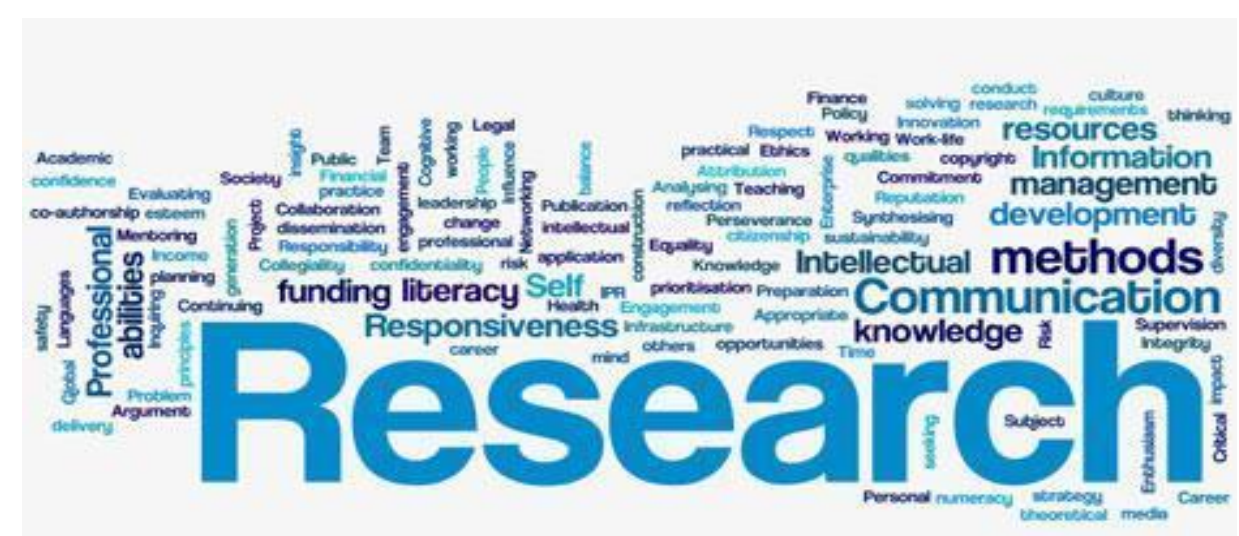

Figure 3. Research context of study

This section defines the study context, primarily where the researcher conducted the study, data collection methods, research participants, and privacy policies taken.

\section{Study Context}

The research study was conducted by creating a survey for participants through the use of Google Surveys. Through the use of emails and Facebook posts and messages, the researcher sent the Google Survey out to a wide network of friends, colleagues, and student teacher candidates to complete the survey. In total, 23 people completed the online survey. The researcher also engaged in conducting interviews for the study context, which were either conducted at Mount Royal University or at Starbucks in Airdrie, Alberta.

\section{Data Collection}

Specific methods of data collection that the researcher used within the investigation were Google Forms that also comprised of collecting responses through a Google Spreadsheet. The spreadsheet manually organized responses accordingly to each question, and listed participants 
as numbers. Another specific method of data collection that the researcher used within the investigation was an iPhone voice recorder to tape conversations with the interviewees. After taping the conversation, the researcher transcribed the interview onto a Microsoft Word document, and listed the participants as numbers, similarly as had been done in the Google Spreadsheet. Therefore, data was gathered either in the Google Spreadsheet, via responses directly from Google Survey, or was gathered into a Microsoft Word document, via responses from the interviews conducted.

The specific context in which the study was conducted was through primarily a school population comprising a majority of participants in the Bachelor of Education program at Mount Royal University, or a student being in another university or technical program. Although the study comprised of a majority of participants being of school population (91\%), a short number of participants (9\%) were other, stating in their responses that they were in the working environment.

\section{Research Participants}

The participants in this research study were comprised of a wide network of friends, colleagues, student-teacher candidates, and university students. Participants were selected based on the allocation of class emails, personal Facebook posts, colleagues re-sharing Facebook posts to help further reach more participants and conducting interviews based on participants having experience with observing technology used by students in the elementary classroom.

The researcher's relationships with the participants in the study ranged from colleagues in the Bachelor of Education program at Mount Royal University, to students in other university or technical program, and friends from Facebook with whom the researcher grew up with during her grade school years. 


\section{Privacy}

Permission and informed consent was gained in the research study through the willingness of participants. In terms of conduct in the Google Survey, participants gave informed consent to take part in the study by either completing or not completing the survey. Before interviews were conducted the participants gave informed consent to take part in the study by expressing verbally their willingness to or to not take part in being interviewed for purposes solely upon the research investigations of my inquiry. The participants from the Google Survey and those interviewed were all adults (18+), therefore other forms of informed consent and permission were not required as a follow-up.

The researcher assured participants that they would be protected from harm and that they would not be exposed to risks by including this information at the beginning of the Google Survey and by verbally providing instructions before conducting the interviews that all comments and statements would be anonymous. The researcher also assured potential candidates that all responses would be kept confidential with no personal information being attached to the study. As well, the researcher obtained the Canadian Human Ethics Research Certificate in order to conduct surveys and interviews. In addition, participants were informed that they would be able to obtain a copy of the final published research once completed. 


\section{Methods of Investigation}

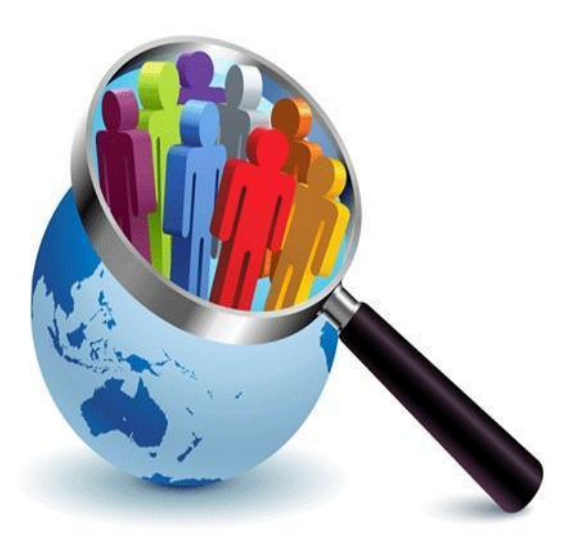

Figure 4. Methods of investigation from research study

This section of the research study defines the researcher's approach to the research design, the position of the researcher on the area of inquiry, the exploration of data, and the organization and analysis of data.

\section{Approach to Research Design}

The general approach taken was an experimental research study. By taking this approach, the questions in the Google Survey and in the interviews conducted were controlled by the researcher. By allowing the researcher to maintain control over the study context, this allowed participants to go deeper into thinking about an inquiry question as opposed to making other inferences, and this allowed the researcher to make judgments on the prediction of the results based on the review of the literature related to the study.

\section{Position of Researcher}

There was an element of bias in this study as the researcher had a personal interest in the topic of inquiry and how it might impact her future practice as an elementary school teacher. Furthermore, the position of the researcher in the area of inquiry is in support of digital technologies being used in the classroom. Observations of students wanting to learn on digital 
devices as opposed to traditional means of pen and paper was observed when students were given the choice, lead the researcher to be in support of a high integration of digital technologies in the elementary classroom.

\section{Exploration of Data}

Data that was explored within the terms of how technologies might initiate and increase student engagement with their learning, and how technology could potentially influence the creation of the 21st century learner. Specific data exploration in terms of background information of participants who were willingly taking part in the research study survey and interviews, comprised of questions being on the participant's educational background, the technological devices that participants owned, and time spent on these digital devices within their daily lives. After the initial participant background questions, specific exploration questions were posed in relation to the area of inquiry. These questions were comprised of participant's personal opinions on skills technology has imparted upon them as opposed to the traditional means of reading and writing, as well as what they believe are the skills required to become a 21st century learner at all levels of grade school in the classroom today. Furthermore, other specific questions asked participants whether they preferred traditional or digital devices to learn, and why participants think people, apart from themselves, are attracted to incorporate technology into their daily lives at home, work, and in life generally.

\section{Organization and Analysis of Data}

Data was organized in this research study through the use of Google Spreadsheets, which was used to collected and manually organized responses accordingly to the question being answered. In reference to the interviews conducted, responses were organized in a Microsoft Word document parallel to the question responses in the Google Spreadsheet. 
The data was analyzed by combining the interview data with the survey responses in the Google Spreadsheet, and then reading all the responses together multiple times to draw out key themes and conclusions. The Wordle application was used to create word clouds for long answer responses in order to draw out key words and themes. By using these different methods of data analysis the researcher was able to triangulate the findings into key themes and ideas.

\section{Findings}

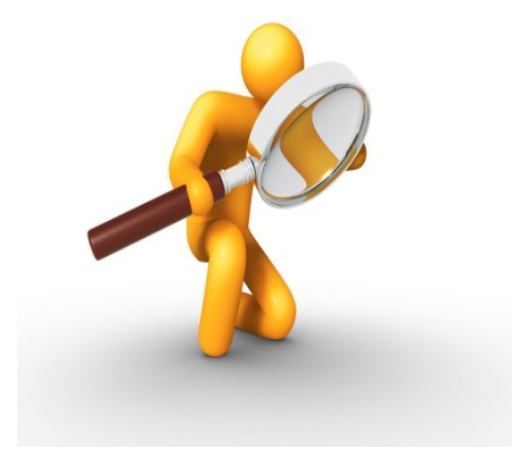

Figure 5. Findings of research study

The findings of this research study were derived from the integration and analysis of the survey and interview question data. The first question investigated the participants' background (Figure 6).

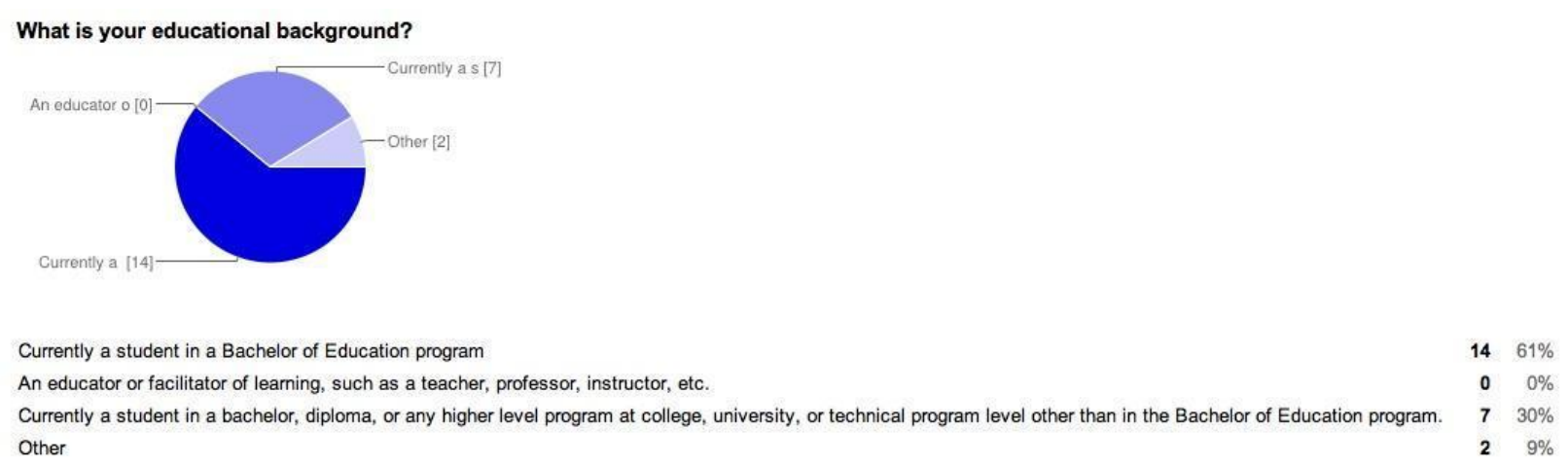

Figure 6. Educational background of participants

The educational background of the people who participated in the online survey ranged from 61\% being a student in the Mount Royal University Bachelor of Education program to 30\% 
being students in another university or technical program other than the Bachelor of Education, In addition, 9\% identified themselves as not being post-secondary students and $0 \%$ were educators or facilitators of learning.

The next question explored the digital device ownership (Figure 7).

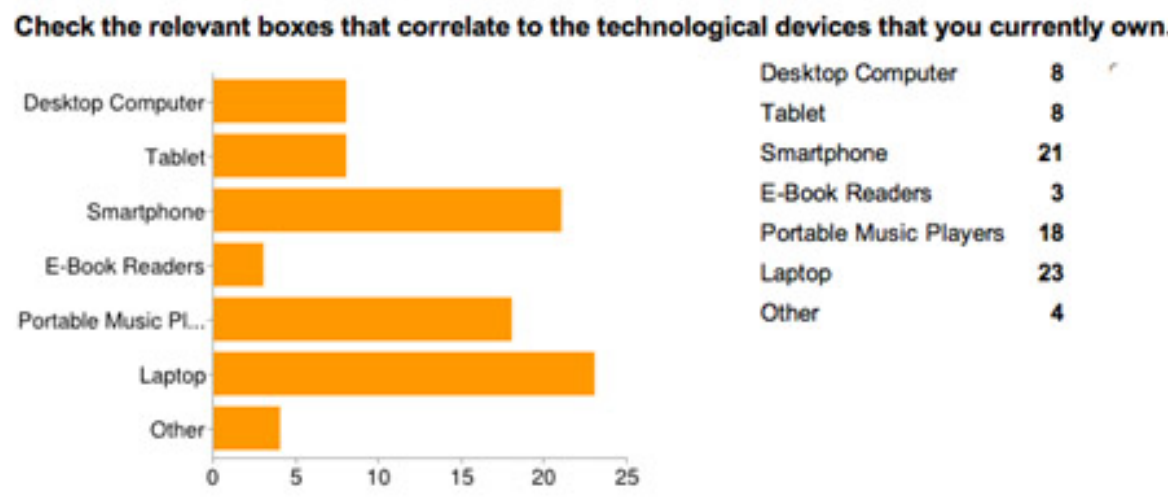

Figure 7. Digital device ownership

All of the research participants owned laptops (100\%) and the vast majority owned Smart phones (91\%). In addition, a large portion owned portable music players (78\%) while only 35\% owned tablets and desktop computers.

The researcher was then curious to discover how many hours a day that the participants spent using their digital devices (Figure 8).

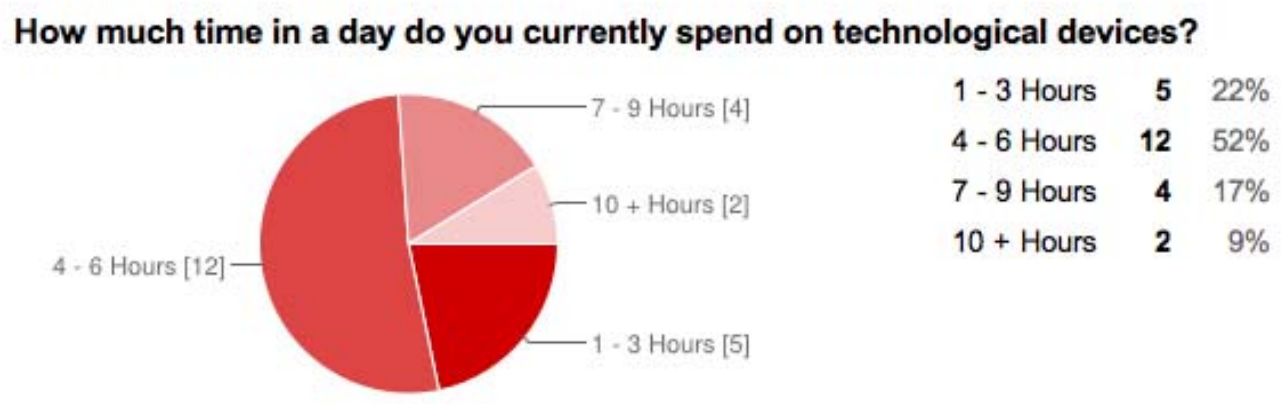

Figure 8. Daily use of digital devices 
The majority of participants reported spending between four to six hours a day using their digital devices (52\%) while 9\% reported using these devices more than ten hours a day.

The next question asked the participants to explain what skills they were learning through the use of their digital devices as opposed to writing handwritten notes, and copying and reading from a textbook. The researcher created a word cloud with Wordle in order to identify key skills from this long-answer question (Figure 9).

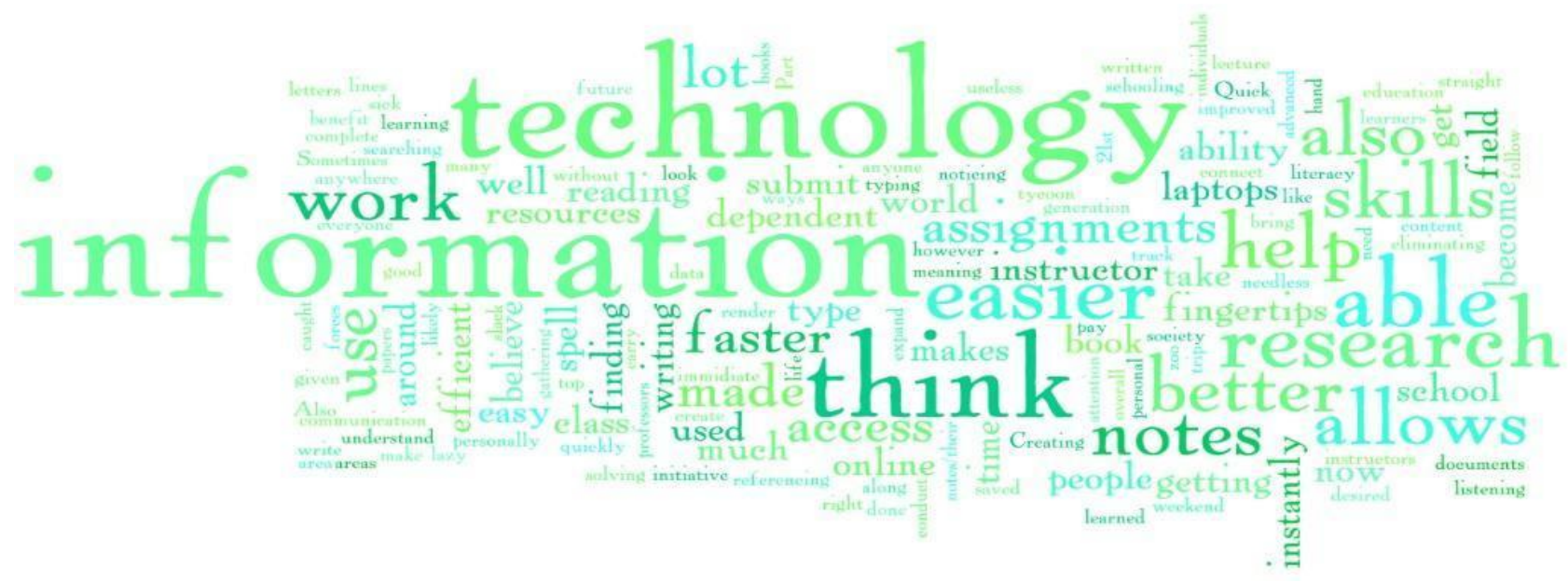

Figure 9. Key skills derived from the use of digital devices

Major themes and conclusions that were drawn from the responses of the research participants to this question included how the use of digital devices could help elementary students to become self-directed learners by allowing them to continually access and evaluate information. This in term could foster critical thinking and problem solving data skills allowing students to become more engaged thinkers, and also influencing their leadership and collaboration skills.

The researcher wanted to further probe the topic regarding what kind of skills are required to become a 21st century learner in the classroom (elementary, middle, and high school) today. This was the focus of analyzing the next survey question, once again using the Wordle application (Figure 10). 


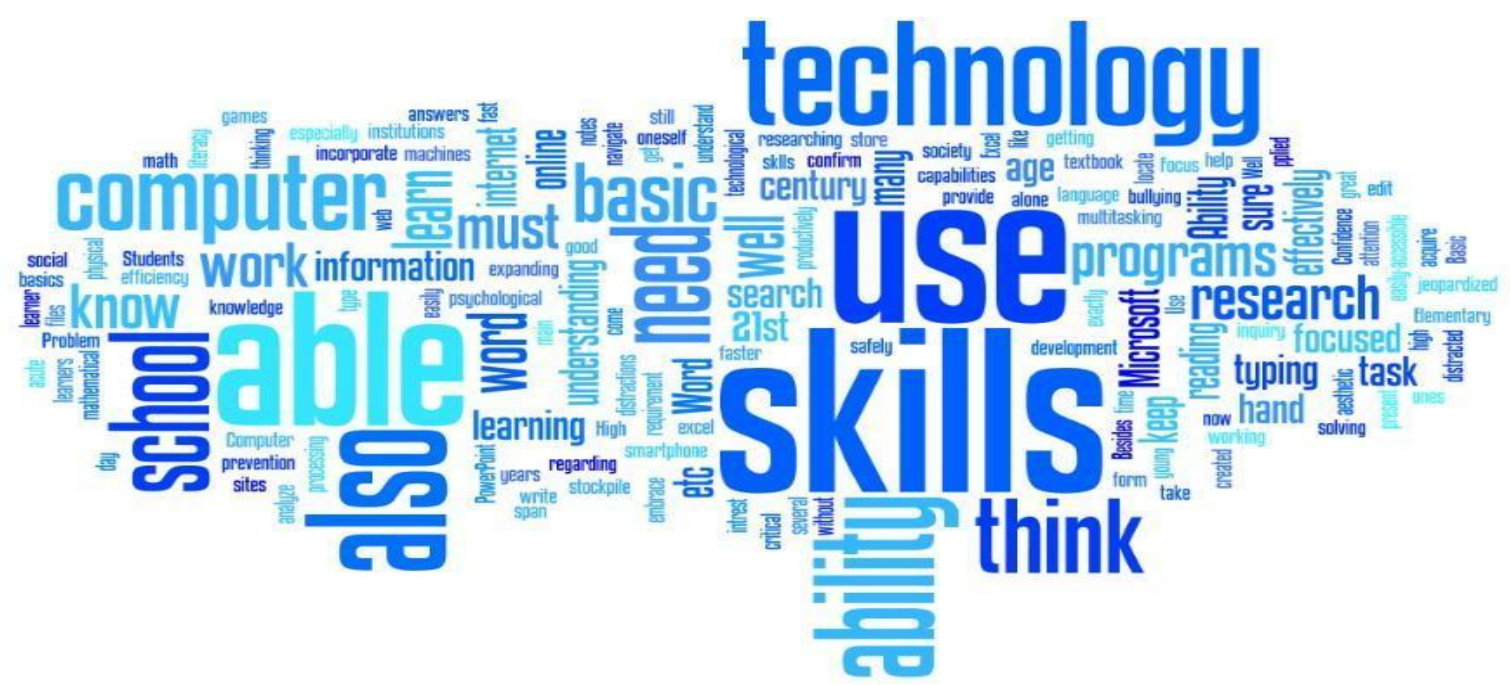

Figure 10. Skills required to become a $21^{\text {st }}$ century learner

Major themes for the participant responses to this question indicated that it was crucial to have typing proficiency and mastery, be able to evaluate and assess data both from textbooks and digital sources. In addition, students should possess research, problem solving, and critical thinking skills, and most importantly to have an open mind and the confidence to learn on their own.

The research participants were then asked if they preferred to learn through the use of digital devices or the more traditional method of reading a printed textbook and writing by hand (Figure 11). Once again, the long-answer responses to this question were analyzed using the Wordle application. 


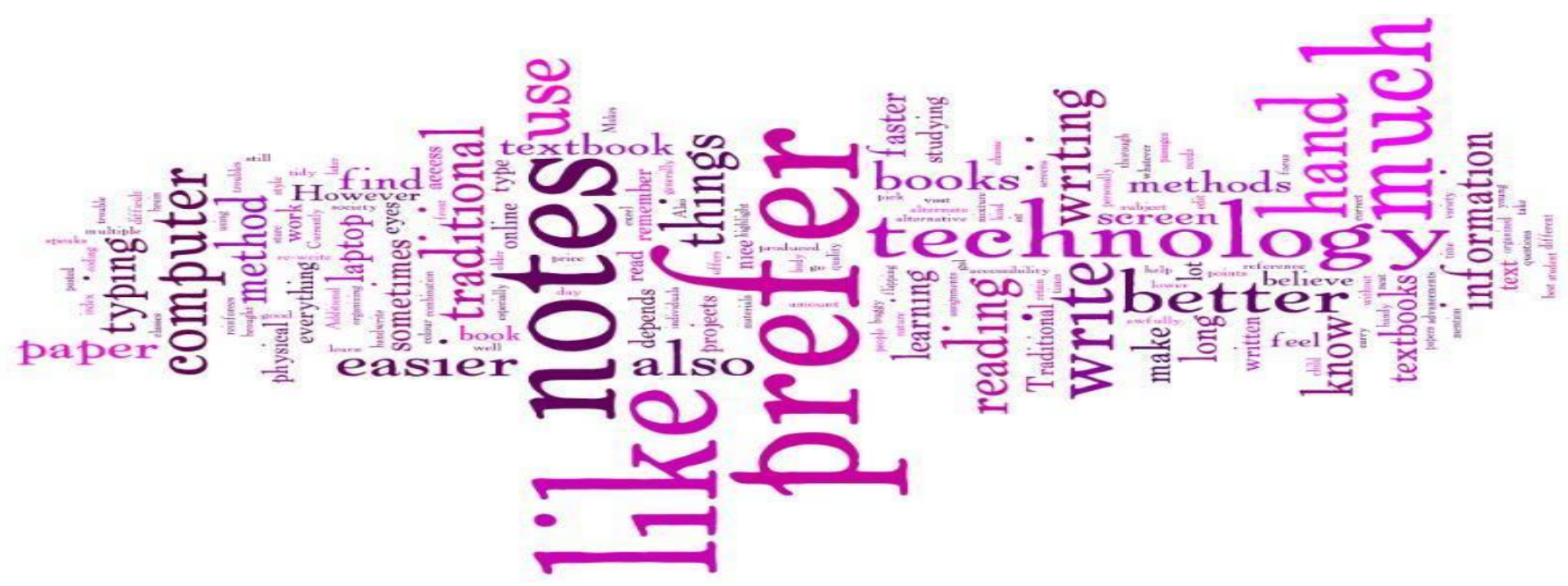

Figure 11. Research participant learning preferences: digital versus traditional

The major themes and conclusions that were drawn from the survey responses to this research question indicate that an overwhelming $83 \%$ of the research participants prefer using digital devices to help them learn. Many participants noted that they were more engaged in their learning when using digital devices as it was easier and faster to create notes and collect information from lectures, and that it was easier to organize and allocate this information and the corresponding notes.

The final survey question asked the participants to reflect about how they incorporate digital devices into their daily lives (Figure 12). Were these devices primarily learning or work tools?

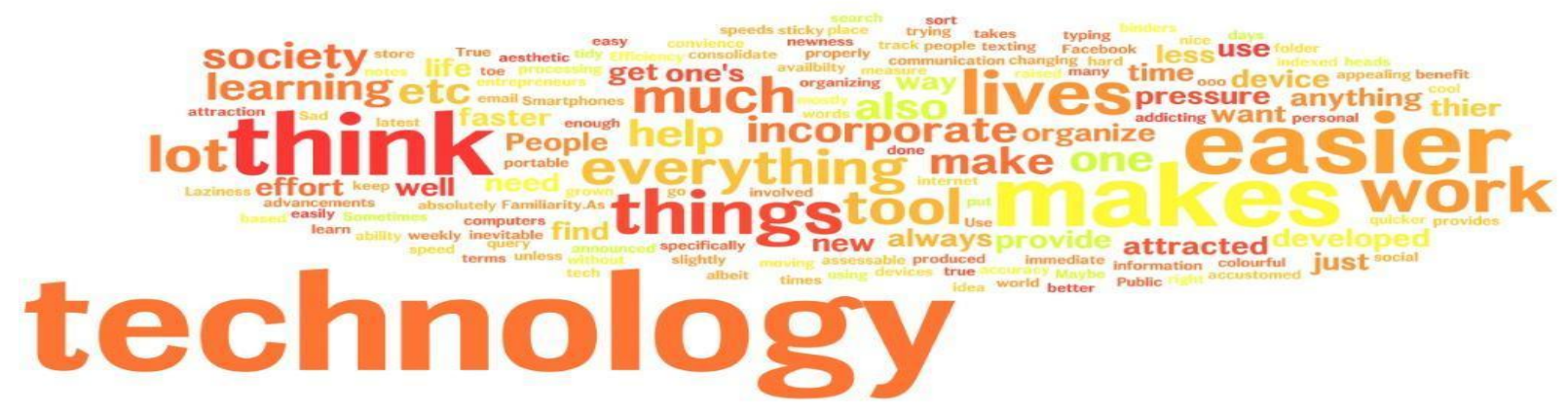

Figure 12. Use of digital devices in participants’ daily lives 
Major themes that were concluded from this inquiry question, when posed to research participants, was that the attraction of technology is noted to be a tool, which is convenient in organizing information, and is efficient in making data easier to access and allocate, relieving pressure from the inability to capture all information when writing by hand in traditional means of learning.

\section{Conclusions and Recommendations}

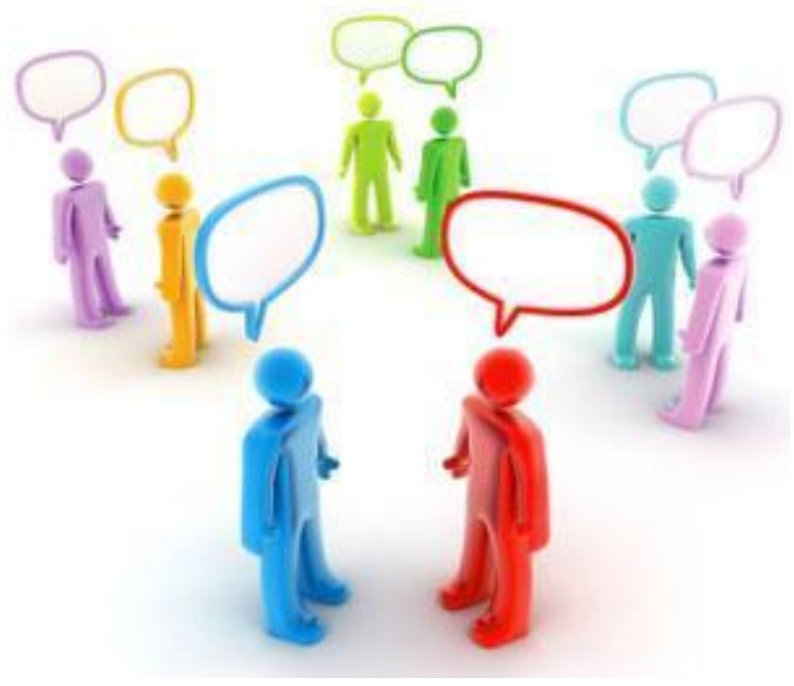

Figure 13. Conclusions and recommendations from research study

The conclusions and recommendations of this research project are comprised of a final analysis of the data in regards to the potential significance of this study on the researcher's future teaching practice as an elementary teacher, and on identifying questions for future inquiry.

\section{Cumulative Analysis}

Final conclusions drawn from the research study's area of inquiry are that technology is increasingly becoming more influential in student's learning occurring in the classroom. As students integrate the use of digital devices more profoundly in their learning, they become more motivated to become engaged in what they are learning in the classroom environment. Therefore the skills that technology has imparted on the creation of the 21st century learner are the ability 
to become self-directed learners with the ability to access an unlimited amount of information through the Internet, and developing leadership and collaboration skills when teaching others to understand and gain competence with new devices and apps. Therefore, it is of the utmost importance that teachers begin to integrate the use of digital devices on a large-scale basis, to not only help learners become more motivated and engaged to want to learn, but to develop a new set of skills, 21st century skills, a direct result of the influence of technology.

\section{Significance on Future Teaching Practice}

This study’s potential significance for the researcher’s future teaching practice as an elementary teacher is that it helped to inform the researcher that digital devices have a profound influence on learners as being a key motivator to their engagement in learning. By understanding that digital technologies can help students to learn easier and more efficiently, the researcher can take this newfound knowledge and integrate the use of digital devices on a more large-scale basis in her own future classroom environment to keep learners engaged in their learning. Throughout her various elementary school placements, the researcher has observed students to continually exhibit the same emotion of wanting to learn using digital devices as opposed to using traditional means such as pencil and paper. By furthering her observations of technology from the classroom into an area of inquiry, the cumulative analysis and findings showcase and further express this significance of students desiring of using digital devices to help them to learn.

Therefore, by keeping this knowledge in mind as a future elementary teacher, the researcher will hopefully be better equipped to teach to the learning styles and motivations of the students to help them succeed in their learning and in their life outside the classroom environment.

\section{Future Research Questions}

Future research questions for inquiry that this study has identified are to further 
investigate the skills that are imparted upon a learner from the traditional learning setting (such as pencil and paper) versus a technology based learning setting (such as iPads, computers, SMART boards, etc.). Another future research question that may be of relevance to pursue is the significance of the skills and time required for teachers to understand the various digital devices in order to implement them into the classroom environment, and whether or not teachers need workshops on these digital devices. Lastly, another future research question that this study has identified for further pursuance is the grade level and/or age that children should start to become exposed to digital devices in order to help them with their learning may also prove to be a beneficial research area of inquiry.

\section{References}

GOOD Worldwide Inc. (2012, May 30). Future learning short documentary [YouTube]. Retrieved from http://www.youtube.com/watch?v=qC_T9ePzANg

Larson, L.C., \& Miller, T.N. (2011). 21st Century skills: Prepare students for the future. Kappa Delta Pi Record, 47, 121-123.

Potnism N. (2013, February 28). Sugata Mitra TED 2013 Winning Talk [YouTube]. Retrieved from http://www.youtube.com/watch?v=zpcEpmNbHds

Saavedra, A.R., \& Opfer, V.D. (2012). Learning 21st-century skills requires 21st-century teaching. Phi Delta Kappan, 94, 8-13. 